\title{
A UTILIZAÇÃO DA SIMULAÇÃO “FORÇA E MOVIMENTO" DA PLATAFORMA PhET, COMO RECURSO DIDÁTICO NO PROCESSO DE ENSINO-APRENDIZAGEM NO ENSINO MÉDIO
}

Swéle Rachel da Silva ${ }^{1}$

Cláudia Adriana de Sousa Melo²

\section{RESUMO}

Este trabalho destina-se a divulgar junto aos professores de Física da série inicial do Ensino Médio a utilização de objetos de aprendizagem fundamentados nas TICs. Então o objeto deste trabalho são as simulações computacionais, em linguagem Java, como recurso no processo de ensino-aprendizagem. Estas simulações apresentam-se como uma boa metodologia para o professor se contrapor ao ensino tradicional (quadro e pincel), no qual impera a oralidade e a escrita. Objetivado descrever esta metodologia realizou-se a aplicação em uma sequência didática sobre o tema "Trabalho de uma força", utilizando-se a simulação disponível na Plataforma PhET - Interactive Simulations da Universidade do Colorado, de forma a propiciar uma aula mais dinâmica e visual. Delimitado ao tema a ser analisado, foi construído dois questionários direcionado aos educados e o outro ao professor para investigar suas opiniões com relação ao conhecimento acerca desse recurso, e finalmente a aplicação da simulação em uma turma do primeiro ano do Ensino Médio, com vinte e nove educandos de uma escola pública do município de Teresina-PI. Conclui-se que a utilizar a familiaridade do educando com o computador apresentou um bom resultado, pois os educandos se mostraram entusiasmado com a alternativa contrária ao modelo tradicional de ensino, onde a fonte de aprendizagem deixa de está apenas no quadro e pincel e na oralidade do professor. Desta maneira a metodologia torna o processo de aprendizagem mais atrativa e construtiva.

Palavras-chave: Ensino de Física. Ensino Médio. Objetos de Aprendizagem.

1 Professora do Programa Mais Educação. Graduada em Física pela Universidade Federal do Piauí. Especialista em Física pela Universidade Aberta do Piauí. E-mail: swelelyn@hotmail. com.

2 Professora Adjunta da Universidade Federal do Piauí. Doutora em Física pela Universidade de São Paulo. E-mail: claudiamelo@ufpi.edu.br. 


\section{USE OF THE SIMULATOR "STRENGTH AND MOVEMENT" OF THE PHET PLATFORM AS EDUCATIONAL RESOURCE IN THE PROCESS OF TEACHING-LEARNING IN MIDDLE SCHOOL PROGRAMS}

\section{ABSTRACT}

This work is intended to be disseminated to the School of the initial series Physics teachers use learning objects based on TICs. So the objects of this work are the computer simulations in Java, as a resource in the teaching-learning process. This simulations are presented as a good methodology for the teacher to oppose the traditional teaching, where the prevailing orality and writing. Objectified describe this methodology application was held in a teaching sequence on the topic "Work of a force", using the simulation available in PhET Platform - Interactive Simulations University of Colorado, in order to provide a more dynamic and visual class. Bordered to the subject to be analyzed, was built two questionnaires directed to the educated and the other the teacher to investigate their opinions with regard to knowledge about this feature, and finally the application of simulation in a class of first year of high school, with twenty nine students of a public school in the city of Teresina-PI. In conclusion, using the familiarity of the student with the computer showed a good result, because the students have shown keen on the contrary alternative to the traditional model of education, where the source of learning stops is just in the frame and brush and orality of teacher. In this way Methodology become more attractive and constructive learning process.

Keywords: Physics Teaching. High school. Learning Objects. 


\section{EL USO DE SIMULACIÓN “FUERZA Y MOVIMIENTO" DE LA PLATAFORMA PhET COMO RECURSO DIDACTICO EN EL PROCESO DE ENSEÑANZA-APRENDIZAJE DE ESCUELA SECUNDARIA}

\section{RESUMEN}

Este trabajo se destina a difundir junto a los maestros de Física de serie inicial de la Escuela Secundaria la utilización de objetos de aprendizaje basados en las TICs. Entonces, el objeto de este trabajo son las simulaciones por ordenador, en lenguaje Java, como recurso en el proceso de enseñanza-aprendizaje. Estas simulaciones se presentan como una buena metodología para el profesor se contraponer a la enseñanza tradicional, ( pizarra y pincel ), donde la oralidad y la escritura prevalece. Objetivado describir esta metodología se llevó a cabo una secuencia didáctica sobre el tema "Trabajo de una fuerza", utilizandose la simulación disponible en la plataforma PhET - Interactive Simulations de la Universidad de Colorado, con el fi n de proporcionar una clase más dinámica y visual. Delimitado al tema a ser analizado, se construyeron dos cuestionarios dirigidos a los educados y el otro al maestro para investigar sus opiniones con respecto a los conocimientos acerca de este recurso, y por último la aplicación de la simulación en una clase de primer año de la escuela secundaria, con veinte y nueve estudiantes de una escuela pública del município de Teresina-PI. En conclusión, el uso de la familiaridad del estudiante con el ordenador mostró un buen resultado, ya que los estudiantes han mostrado interesados con la alternativa contraria al modelo tradicional de enseñanza, donde la fuente de aprendizaje deja de ser sólo la pizarra, el pincel y la oralidad del maestro. De esta manera la metodología hace que el proceso de aprendizaje sea más atractivo y constructivo.

Palabras clave: Enseñanza de Física. Escuela Secundaria. Objetos de Aprendizaje. 


\section{INTRODUÇÃO}

A sociedade atual passa por uma efervescência tecnológica, o que torna necessário o professor adaptar-se a essa mudança na velocidade de transmissão da informação e da comunicação. $\mathrm{Na}$ sociedade contemporânea, decisões políticas tendem a girar em torno do problema e questões relacionados direta ou indiretamente com o conhecimento científico e tecnológico (JUCA, 2013).

Desse modo, corroborando com as Leis de Diretrizes e Bases da Educação Nacional de nº 9.394 de 20 de dezembro de 1996 que diz "[...] os conteúdos, as metodologias e as formas de avaliação serão organizados de tal forma que ao final do ensino médio o educando demonstre: domínio dos princípios científicos e tecnológicos que presidem a produção moderna [...]." (BRASIL, 1996).

É sabido que nas escolas, encontram-se estudantes atraídos e até mesmo seduzidos pela tecnologia, do outro lado, encontramse professores e suas dificuldades para acompanhar o atual processo evolutivo metodológico. Pode-se notar que a educação passa por uma acentuada mudança de estado onde paradigmas precisam ser quebrados tais como: construção mútua de conhecimento, metodologias mais interativas e etc.

O professor pode acompanhar tais mudanças ao adequar os seus procedimentos e o sistema de avaliação em sala de aula de acordo com a realidade da escola que atua. A Educação tecnológica, por ser realizada em múltiplos contextos, necessita acontecer no campo social, a fim de que as experiências possam ser trocados em um processo de reconstrução significativa e de mútuas mudanças (JUCA, 2013).

Os conteúdos de Física, na maioria das vezes, têm recebido um tratamento abstrato e fora da realidade do aluno, e o professor tornase basicamente um mero transmissor de informações, transformando o educando em um ser passivo e impossibilitando-o de ser um cidadão cientificamente crítico. 
A esse respeito, os $\mathrm{PCN}+$ dizem que "[...] A escola não pode ficar alheia ao universo informatizado se quiser de fato integrar o estudante ao mundo que o circunda [....]." (BRASIL, 2002, p. 225).

Neste contexto, a chamada forma tradicional de ensino acaba gerando agentes passivos no processo de ensino aprendizagem, e fica difícil avaliar se o método empregado é, de fato, eficiente. Pergunta-se: será que os estudantes estão conseguindo desenvolver suas percepções e reflexões pessoais? Faz-se necessário quebrar esta barreira de agentes passivos, isto é, os estudantes precisam aprender a visualizar um fenômeno físico e, a partir disso, levantar hipóteses criticar modelos a eles apresentados (VOGLER, 2004).

É sabido, que estudantes desenvolvem interpretações sobre o mundo físico, de acordo com suas próprias experiências, muito antes do primeiro contato com a disciplina de ciência em geral. Essas interpretações baseadas em suas experiências, que nem sempre são adequadas, e acabam interferindo no aprendizado de modelos científicos introduzidos nas aulas, principalmente em Física, e consequentemente afetam a habilidade de assimilação das ideias cientificamente adequadas. Seria possível propor uma solução para este problema?

Uma excelente alternativa para motivar os estudantes para as aulas de Física são as atividades em laboratórios de ensino, onde é possível fornecer aos estudantes a possibilidade da montagem de modelos experimentais sobre os mais variados fenômenos físicos, e então, poder comprovar os modelos físicos descritos nas aulas teóricas. A segunda alternativa, viável para a melhoria deste processo de ensino, refere-se ao uso de computadores em sala de aula. Quando este tema é abordado, em momento algum, está sendo questionada a eficiência dos experimentos de Física em laboratórios, mas sim, introduzir outro método que também possa trazer melhorias no processo de ensinoaprendizagem. (VOGLER, 2004; MEDEIROS, 2002) 


\section{O computador como ferramenta didática no ensino de Física}

Ocomputadoréumpoderosoinstrumentodeaprendizagem e pode ser um grande parceiro na busca do conhecimento, podendo ser usado como uma ferramenta de auxílio no desenvolvimento cognitivo do educando, desde que se consiga disponibilizar um ambiente de trabalho, onde os educandos e o professor possam desenvolver aprendizagens colaborativas, ativas, facilitadas, que propiciem ao aprendiz construir a sua própria interpretação acerca de um assunto, internalizando as informações para construir determinado conhecimento (MACÊDO et al., 2012).

Desta maneira, os recursos computacionais surgem como uma das alternativas que podem minimizar os ruídos na comunicação aluno-professor e fomentar a interação aluno-aluno, na perspectiva de Vygotsky, as interações sociais são indispensáveis ao desenvolvimento cognitivo (JUCA, 2013; FERRACIOLI et al., 2012).

É notório que um dos fatores que pode e deve estar contribuindo de forma direta entre o entendimento do aluno sobre o tema abordado e a situação exposta pelo professor refere-se aos ruídos na comunicação aluno-professor, tais como: a abstração dos modelos físicos, a falta de interesse do aluno e, acima de tudo, a falta de conexão entre a Física ensinada na sala de aula com a Física do cotidiano, devemos ressaltar que os computadores mostram um grande potencial no desenvolvimento e aquisição de conhecimentos, desde que usado de forma apropriada, como parte integrante no processo de ensinoaprendizagem. (VOGLER, 2004).

Um exemplo do uso de computadores em sala de aula diz respeito a simulações de fenômenos físicos, utilizando para tanto uma linguagem de programação no desenvolvimento dos projetos. Uso de computadores possibilita o estudante rever o conteúdo quantas vezes achar necessário. Mas, como prover o acesso ao estudante? Uma boa opção, sem dúvida nenhuma, é disponibilizar o conteúdo desejado na WEB (são aplicativos que recebem este nome porque são executados na 
internet). A proposta é tornar possível o acesso através de um browser (programa desenvolvido para permitir a navegação pela web, capaz de processar diversas linguagens, como HTML, ASP, PHP), onde o estudante possa interagir com a simulação, fazendo o download da simulação desejada e armazena lá - para uso quando deseja mesmo não estando conectado com a internet. Isso é possível através de Applets Java, que possui um código de acesso livre de fácil manipulação, ou seja, são programas complexos no âmbito de uma página WEB, estes Applets se programam e beneficiam-se desse código livre nas redes. Como será descrito na próxima seção (FAPERJ, 2000).

\section{Simulação "Força e Movimento"}

\section{- Linguagem Java}

Java é uma linguagem que herdou muitas de suas características do $\mathrm{C}++$ e implementa o paradigma da Programação Orientada a Objetos. É uma linguagem interpretada, o que a torna independente da plataforma, ou seja, um mesmo programa pode ser executado em qualquer sistema que possua seu interpretador (FAPERJ, 2000).

A linguagem Java foi desenvolvida pela Sun MicroSystems, objetivando-se aplicações voltadas para produtos eletrônicos de grande consumo, tais como televisões, videocassetes e outros eletrodomésticos. A escolha desse ramo não obteve o sucesso desejado, no entanto, com a popularização da Internet e suas páginas Web. As possibilidades para artes gráficas, multimídia e interação passaram a ser maiores, pois a linguagem Java permite desenhar figuras, fazer cálculos, enviar mensagem ao usuário, exibir janelas e gráficos etc. (FAPERJ, 2000).

O uso da simulação nas aulas de Física merece um olhar mais específico no que diz respeito ao uso como objeto de aprendizagem, então este trabalho propõe-se a apresentar o uso da simulação computacional em uma aula de Física do $1^{\circ}$ ano do Ensino Médio de uma escola pública de Teresina - PI com o tema Trabalho de 
uma força. Alicerçada na aplicação do questionário antes da aplicação da simulação com os educandos, para título de conhecimento do uso das simulações nas aulas de Física (FAPERJ, 2000).

Dentre as simulações disponíveis na internet que tivemos a oportunidade de analisar e catalogar, optamos pela simulação "Força e Movimento" da plataforma PhET-Interactive Simulations da Universidade do Colorado. Como mostra a figura 1

Figura 1- Simulação do fenômeno Força e Movimento

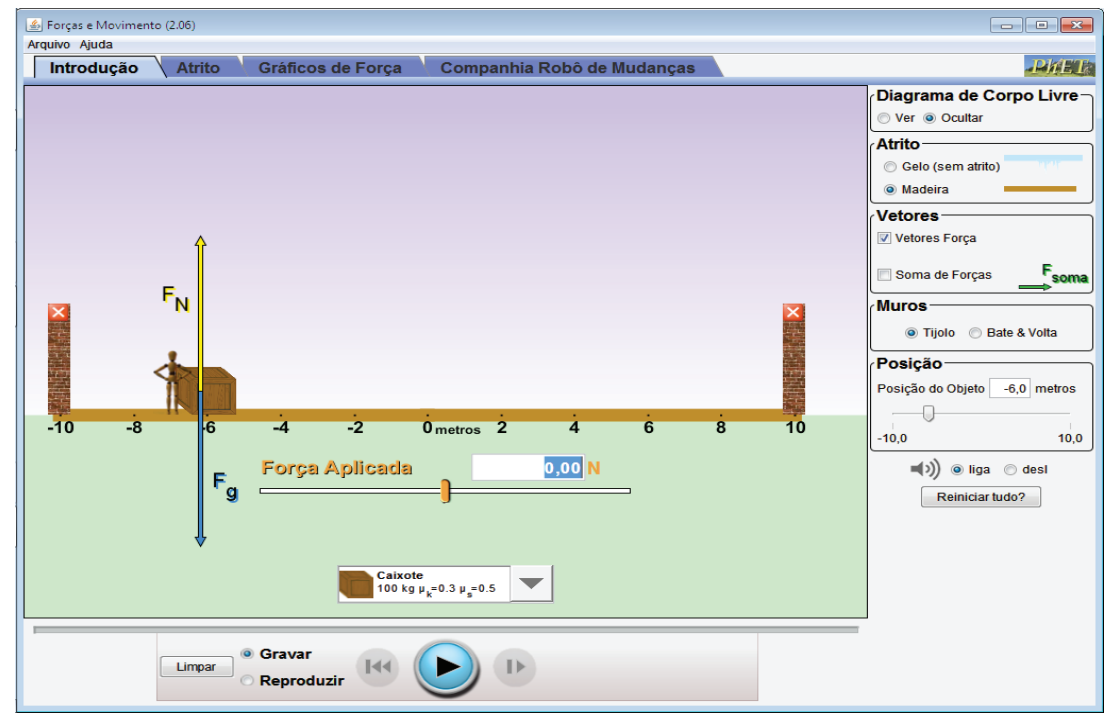

Fonte: https://phet.colorado.edu/pt_BR/simulations/category/physics.

A PhET oferece gratuitamente simulações de fenômenos físicos, de acordo com sua equipe:"[...] oferece gratuitamente simulações de fenômenos físicos divertidos, interativas e baseadas em pesquisas [...]" ( PHET, 2016) . Logo abaixo na figura 2 temos a plataforma PhET traduzida para o português, onde do lado esquerdo encontra-se as simulações da área da Física identificadas por nomes. 
Figura 2 - Site de PhET - Universidade do Colorado

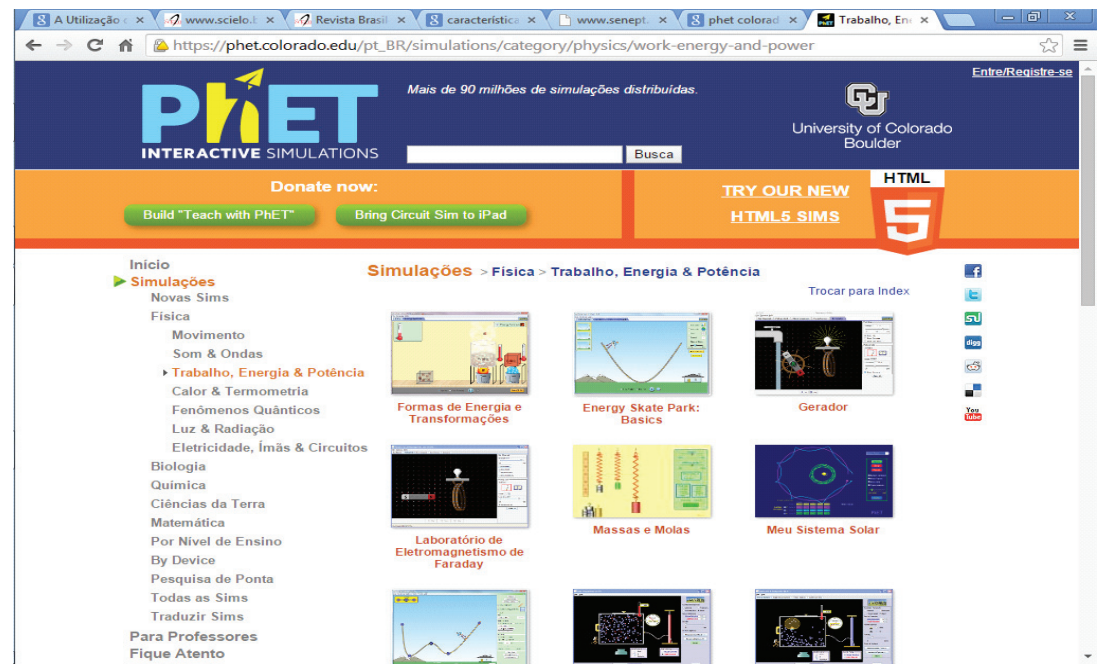

Fonte: https://phet.colorado.edu/pt_BR/simulations/category/physics.

Tornando assim a simulação um objeto de aprendizagem que consiste em ser uma efetiva ferramenta de aprendizagem com a finalidade pedagógica de introduzir um novo tópico, construir conceitos, competências, reforçar ideias ou fornecer reflexão. O uso dessa ferramenta por professores pode ser bastante variado tais como: aulas expositivas, atividades em grupo em sala de aula, tarefas em casa ou no laboratório (ARANTES et al., 2010).

As simulações computacionais tiveram seus primórdios na Segunda Guerra Mundial. Computadores como o Mark I e o ENIAC, da marinha e do exército norte-americanos, respectivamente, foram utilizados para cálculos balísticos naquele período, buscava-se simular o lançamento de mísseis (BALADEZ, 2009). Como mostra a figura 3 : 
Figura 3 - ENIAC do exército norte americano.

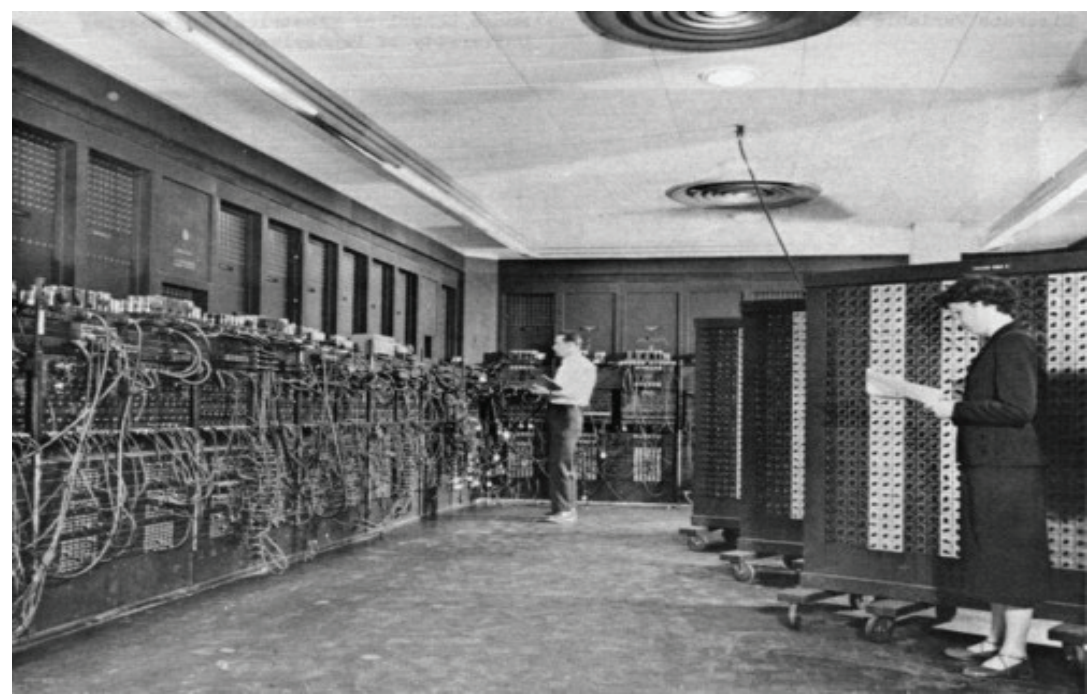

Fonte: http://www.hardware.com.br/guias/historiainformatica/eniac.html.

O desenvolvimento das simulações computacionais na década de 50, ainda para fins militares, eram realizados por grandes e lentos computadores, programados em linguagem Fortran IV, processando softwares puramente textuais (JUCA, 2013; BALADEZ, 2009).

Neste contexto, a Inserção das TICs (Tecnologias da Informação e Comunicação) deve facilitar a interação nas atividades do Ensino de Física, tornando possível ilustrar situações que são difíceis para serem demonstradas apenas com recursos didáticos tradicionais como quadro e pincel (VOGLER, 2004).

\section{Metodologia}

Esta seção foi dividida em quatro etapas: a catalogação de simulações disponíveis para a área da Mecânica na plataforma PhET; a construção do questionário com perguntas dicotômicas e perguntas e de múltipla escolha direcionado aos educandos para investigar suas 
opiniões com relação e o conhecimento que apresentam acerca do objeto de aprendizagem em questão, o questionário do docente para averiguar se o mesmo faz uso desse recurso didático em suas aulas, foi construído com perguntas dicotômicas e de múltipla escolha (MARCONI; LAKATOS, 2003), e finalmente a aplicação da simulação em uma sala de primeiro ano do Ensino Médio contendo vinte e nove alunos onde o professor atual nunca utilizou este recurso em suas aulas.

\section{- Relação dos Simuladores catalogadas}

As dezessetes simulações catalogadas encontram-se disponível na tabela 1 nomeadas e enumeradas, desta forma o professor pode localizar o que cada simulação aborda, podendo incluir a simulação que deseja em seu planejamento, fazendo com que suas aulas tornemse mais dinâmicas. Quanto aos objetivos didáticos de cada simulação podem ser encontradas na plataforma PhET.

Tabela 1 - Organização das simulações catalogadas

\begin{tabular}{|l|l|}
\hline NOME - SIMULAÇÃo & TÓPICOS ABORDADOS \\
\hline 1 - Movimento em 2 D & Movimento, velocidade e aceleração. \\
\hline 2 - O homem em movimento & Posição, velocidade e aceleração. \\
\hline 3 - Movimento de projéteis & $\begin{array}{l}\text { Ângulo, velocidade inicial, massa e resistência do } \\
\text { ar. }\end{array}$ \\
\hline 4 - Meu sistema solar & $\begin{array}{l}\text { Movimento, aceleração, velocidade, posição } \\
\text { gravidade. }\end{array}$ \\
\hline 5 - Força e movimento & Força, posição, velocidade e aceleração. \\
\hline 6 - Giro 2D joaninha & Posição, velocidade e aceleração. \\
\hline 7 - Forças e movimento & $\begin{array}{l}\text { Força, movimento, fricção, velocidade, primeira } \\
\text { Lei de Newton. }\end{array}$ \\
\hline 8 - Força em uma dimensão & Força, posição, velocidade e aceleração. \\
\hline 9 - Massa e molas. & $\begin{array}{l}\text { Molas, lei de Hooke, energia de conservação e } \\
\text { medida. }\end{array}$ \\
\hline 10 - Rampa & Força, energia e trabalho. \\
\hline
\end{tabular}




\begin{tabular}{|c|c|}
\hline $\begin{array}{l}11 \text { - Parque energético de } \\
\text { Skatistas }\end{array}$ & $\begin{array}{l}\text { Energia, energia de conservação, energia cinética } \\
\text { potencial e fricção. }\end{array}$ \\
\hline 12 - Atrito & Fricção, termodinâmica e calor. \\
\hline 13 - Pressão fluxo e fluido & $\begin{array}{l}\text { Pressão, água, fluídos, dinâmica dos fluídos, } \\
\text { Bernoulli e densidade. }\end{array}$ \\
\hline $\begin{array}{l}14 \text { - Laboratório de força } \\
\text { gravitacional }\end{array}$ & Força e gravidade. \\
\hline 15 - Flutuabilidade. & Empuxo e densidade. \\
\hline 16 - Jogo do labirinto & Posição, velocidade e aceleração. \\
\hline 17 - Adição de vetores & Vetores e soma de vetores. \\
\hline
\end{tabular}

Fonte: https://phet.colorado.edu/pt_BR/simulations/category/physics/motion.

\section{- Introdução antes do uso da Simulação}

Foram ministradas duas aulas, considerando que na primeira foi uma aula expositiva sobre a teoria relacionada com a simulação. Na segunda aula foi uso efetivo da simulação da plataforma PhET como recurso de didático, porém no primeiro momento foi realizado alguns questionamentos antes de iniciar a aula com os educandos, questionamentos esses descritos abaixo, sendo que os mesmos foram feitos sem a formalidade dos questionários citados nas tabelas 2 e 3 (MACÊDO et al., 2012; MEC, 2009).

Qual o significado da palavra Força para vocês?

- Quando se fala em Força no que vocês pensam?

- Para que serve a Força?

Algumas respostas surgiram, tais como: "[...] a Força é algo que produz movimento [...]", "[...] Força é quando tentamos empurrar um objeto de um lugar pra outro [...]" (dois educandos de 15 anos, Informação verbal).

Após a identificação do que os educandos pensavam e entendiam sobre Força, foi utilizada a simulação Força e Movimento 
para melhor compreensão deste recurso na aula de Física, a visualização do fenômeno pôde ser visto na figura 4. Nesse momento considerouse importante que os mesmo conhecessem os principais recursos da simulação, sendo eles: possibilidade de mudanças da superfície de atrito (gelo ou madeira), escolha da soma de vetores e escolha da distância (m) do objeto (caixote).

Figura 4 - Página inicial da simulação Força e Movimento

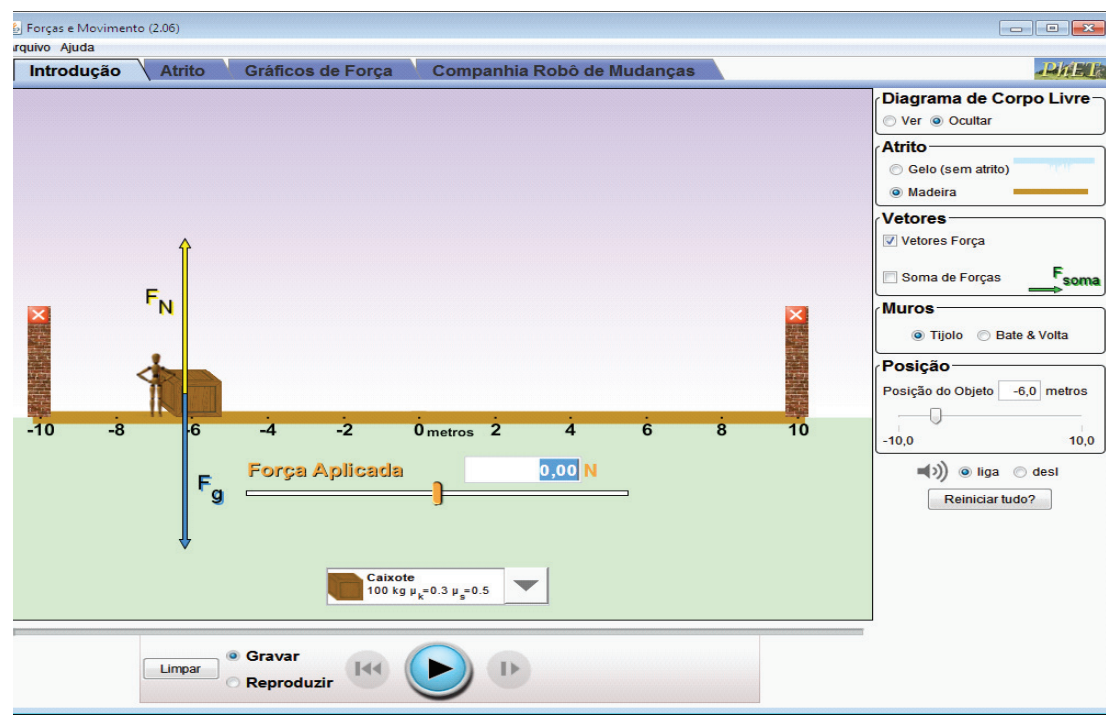

Fonte: Print Computador Samsung: Simulador sendo executado no computador.

Consequentemente, com a simulação em execução como mostra a figura 5, foi posicionado o Marrom $^{3}$ em uma posição inicial para o mesmo realizasse uma força $(F=500 \mathrm{~N})$ onde o caixote encontrase em cima de uma superfície de madeira, ao aplicar uma força sobre o caixote que possui uma massa de $100 \mathrm{~kg}$, em seguida foi pedido que os educandos medissem o tempo gasto que ${ }^{1}$ Marrom utilizou para deslocar o caixote, utilizando o relógio ou cronômetro do celular.

3 Marrom - nome dado pelos educandos ao boneco da simulação da plataforma PhET. 
Figura 5 - Simulação sendo executada

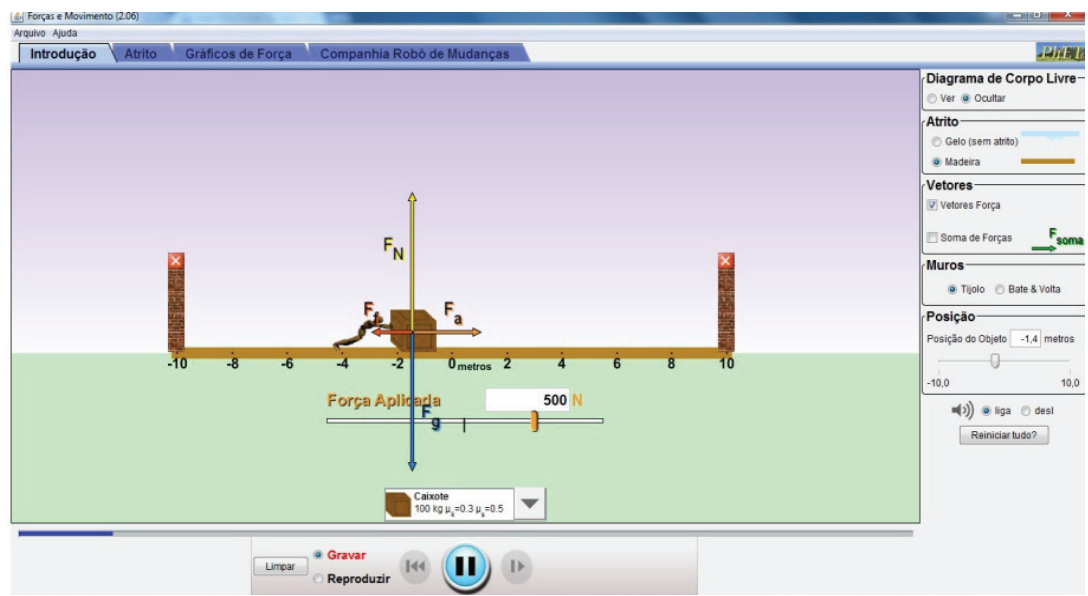

Fonte: Print computador Samsung: Simulação sendo executado no computador.

A simulação possibilita observar o comportamento de outras variáveis, para essa averiguação foi solicitado aos discentes que sugerissem outros valores a força, esse procedimento permitiu a observação do tempo gasto utilizado pelo ${ }^{1}$ Marrom ao deslocar o caixote, como mostra a figura 6 .

Figura 6 - Simulação sendo executada

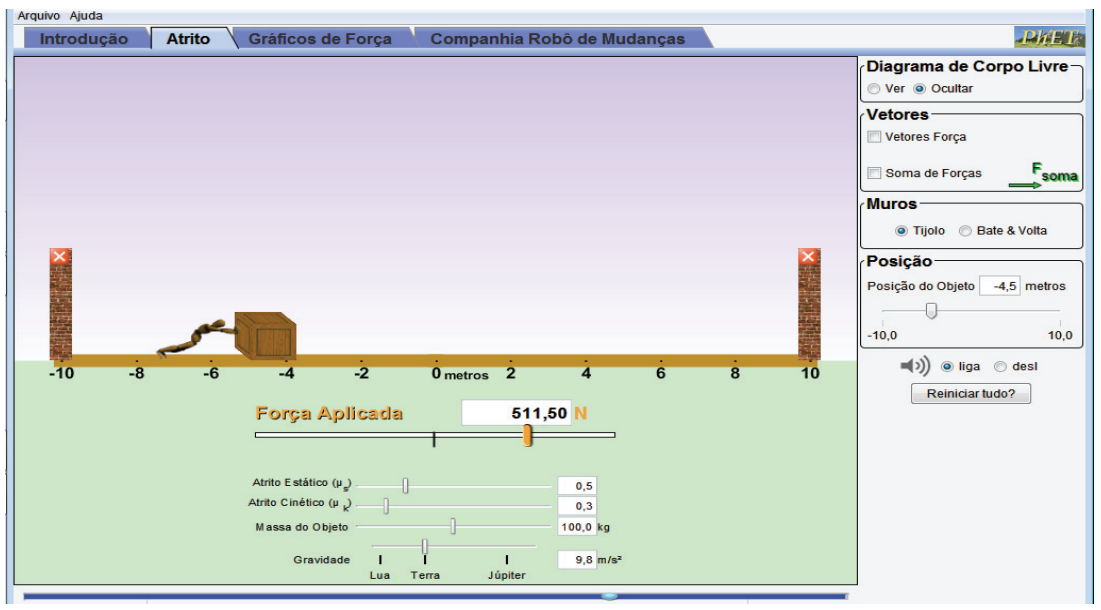

Fonte: Print computador Samsung: Simulação sendo executado no computador. 
Assim iniciamos a ideia de força, e esta associada ao trabalho, que por sua vez relaciona-se ao intervalo de tempo gasto utilizado pelo ${ }^{1}$ Marrom. E no campo da Física denomina-se de potência média e seu valor pode ser encontrado utilizando a fórmula Matemática abaixo (BLAIDI et al., 2010):

$$
P_{m=\frac{W}{\Delta t}}
$$

Foi esclarecido que o ${ }^{1}$ Marrom, ao aplicar uma força sobre o caixote, realizou trabalho implicando em uma potência média, onde sua unidade de medida no SI (Sistema Internacional de Unidade) é representada em $\mathrm{J} / \mathrm{s}$, onde denomina-se de watt em homenagem ao engenheiro escocês James Watt que viveu no século XVIII (CARDOSO et al., 2012).

É relevante ressaltar que o livro texto "Conexões com Física" utilizado na escola é direto quanto à abordagem do dado assunto. $\mathrm{O}$ livro apresenta um único exercício resolvido. Não apresenta nenhuma abordagem com aplicabilidade do assunto no dia a dia (BLAIDI et al., 2010).

\section{Resultados e discussões dos questionários (Professor e Educandos)}

Nas aplicações realizadas tanto do questionário do professor, quanto dos educandos foram obtidas informações de extrema relevância para o cenário do Ensino de Física com objetos de aprendizagem em linguagem Java, em Teresina. Com as respostas fornecidas, pôde-se notar uma aceitação bem acentuada por parte do alunado, em relação ao uso de simulações nas aulas de Física. Para melhor observação, os dados obtidos e o detalhamento estão na tabela 2 abaixo: 
Tabela 2 - Respostas do questionário aplicado aos 29 alunos do $1^{\circ}$ ano Médio do Ensino Médio

\begin{tabular}{|c|c|c|c|c|c|}
\hline $\mathrm{N}^{\circ}$ & Perguntas & \multicolumn{4}{|c|}{ Respostas } \\
\hline \multirow[t]{2}{*}{1} & \multirow{2}{*}{$\begin{array}{l}\text { Em sua opinião, os conceitos } \\
\text { de Física que são dados em } \\
\text { sala de aula são? }\end{array}$} & $\begin{array}{l}\text { Muito } \\
\text { abstrato }\end{array}$ & $\begin{array}{l}\text { Nem } \\
\text { fácil nem } \\
\text { difícil }\end{array}$ & Difícil & Fácil \\
\hline & & $62 \%$ & $10 \%$ & $28 \%$ & $0 \%$ \\
\hline \multirow[t]{2}{*}{2} & \multirow[t]{2}{*}{$\begin{array}{l}\text { Você acha que uso das } \\
\text { simulações facilitaria o } \\
\text { aprendizado em Física? }\end{array}$} & $\begin{array}{l}\text { Não } \\
\text { facilita }\end{array}$ & $\begin{array}{c}\text { Facilita } \\
\text { um } \\
\text { pouco }\end{array}$ & Facilita & $\begin{array}{c}\text { Facilitaria } \\
\text { muito }\end{array}$ \\
\hline & & $7 \%$ & $10 \%$ & $21 \%$ & $62 \%$ \\
\hline \multirow{2}{*}{3} & \multirow{2}{*}{$\begin{array}{l}\text { Algum professor já fez uso do } \\
\text { simulador nas aulas de Física? }\end{array}$} & \multicolumn{2}{|c|}{ Sim } & \multicolumn{2}{|c|}{ Não } \\
\hline & & \multicolumn{2}{|c|}{$72 \%$} & \multicolumn{2}{|c|}{$28 \%$} \\
\hline \multirow[t]{2}{*}{4} & \multirow{2}{*}{$\begin{array}{c}\text { O que você acha do professor } \\
\text { utilizar esse recurso em suas } \\
\text { aulas? }\end{array}$} & \multicolumn{2}{|c|}{ Muito relevante } & Relevante & $\begin{array}{c}\text { Não } \\
\text { relevante }\end{array}$ \\
\hline & & \multicolumn{2}{|c|}{$55 \%$} & $35 \%$ & $10 \%$ \\
\hline \multirow{2}{*}{5} & \multirow{2}{*}{$\begin{array}{c}\text { Gostaria que as simulações } \\
\text { fossem utilizadas nas aulas de } \\
\text { Física? }\end{array}$} & \multicolumn{3}{|c|}{ Sim } & Não \\
\hline & & \multicolumn{3}{|c|}{$97 \%$} & $3 \%$ \\
\hline \multirow[b]{2}{*}{6} & \multirow{2}{*}{$\begin{array}{c}\text { Você acha que a simulação } \\
\text { melhoraria sua assimilação } \\
\text { nas aulas de Física? }\end{array}$} & \multicolumn{3}{|c|}{ Sim } & Não \\
\hline & & \multicolumn{3}{|c|}{$72 \%$} & $28 \%$ \\
\hline
\end{tabular}

Fonte: Próprio autor.

O resultado evidenciou que os educandos, de fato, acham a Física uma ciência abstrata apesar de se tratar de estudos de fenômenos descritos pela natureza. Eles acreditam que essa dificuldade seria solucionada ou amenizada pelo uso das simulações nas aulas.

Verificou-se também que os educandos, já tiveram contato com a interatividade que as simulações são capazes de proporcionar ao estudar um fenômeno físico, provavelmente com educador anterior ao entrevistado. Nota-se também que os educadores já reconheceram que as simulações computacionais disponíveis na internet de forma gratuita vão além das simples animações. Elas englobam uma vasta 
classe de tecnologias, do vídeo a realidade virtual, que proporciona uma compreensão melhor da Física de forma interatividade (HECKLER et al., 2017).

Porém, no resultado obtido, na entrevista, com professor, podemos notar que suas respostas são contraditórias, podemos analisálas melhor na tabela 3.

Tabela 3 - Perguntas e respostas do docente

\begin{tabular}{|c|c|c|}
\hline No & PERGUNTA & RESPOSTA INFORMADA \\
\hline 1 & $\begin{array}{c}\text { Você fez ou faz uso de simuladores em } \\
\text { suas aulas com quê frequência? }\end{array}$ & nunca usei. \\
\hline 2 & $\begin{array}{r}\text { Você acha que uso do simulador facilita o } \\
\text { aprendizado em Física? }\end{array}$ & facilita muito. \\
\hline 3 & $\begin{array}{r}\text { Você acha importante o uso deste } \\
\text { recurso como intervenção didática? }\end{array}$ & muito importante \\
\hline 4 & $\begin{array}{r}\text { Você acha que os alunos assimilarão } \\
\text { melhor o assunto com uso deste recurso? }\end{array}$ & sim \\
\hline
\end{tabular}

Fonte: Próprio ao autor.

Observou-se que o professor entrevistado da atual turma, embora afirme ser relevante o uso das simulações como recurso, o mesmo nunca usou em sua turma, tornando suas respostas contraditórias, no que diz respeito à importância acentuada que atribui para o uso da simulação computacional. Durante a entrevista, notou-se um certo incômodo quando questionado se fazia uso de outro recurso didático que não fosse às simulações. Respondeu da seguinte forma: "Preparo minhas aulas, mas pra escolher uma simulação requer um melhor preparo e mais tempo coisa que eu não tenho" (Professor de 25 anos).

Contudo, pôde-se notar uma falta de tempo por parte do mesmo, mas é importante salientar que o professor pode "até perder certo tempo" procurando uma melhor simulação ou outro recurso que 
se enquadre em sua aula, mas depois de planejada ganhará o tempo em sala principalmente se o mesmo ministrar a mesma aula na mesma série mais de uma vez no dia.

\section{Conclusão}

Verificamos com este trabalho que a aplicação da simulação em linguagem Java fornecida de forma gratuita na plataforma PhET funciona como objeto de aprendizagem, podendo ser executada em qualquer sistema operacional exceto no sistema operacional Android, a simulação utilizada corresponde ao campo da Mecânica, que pode ser utilizada no $1^{\circ}$ ano do Ensino Médio nas aulas de Física da Educação Básica, sendo, portanto notório a viabilidade da utilização, aceitação por parte dos educandos entrevistados e as diversas possibilidades de exploração.

Quanto à investigação da aplicação da simulação pôde-se concluir que:

Utilizar a familiaridade do educando com o computador a seu favor apresentou um bom resultado, onde os educandos mostraram-se entusiasmados com a alternativa contrária ao modelo tradicional de ensino, onde a fonte de aprendizagem deixa de estar apenas na oralidade do professor.

O computador pode-se tornar algo importante em sala e deixar de ser algo obsoleto ou mais um recurso de ensino cuja utilização não surtiu o efeito esperado, devemos atrelálo a um planejamento de ensino reflexivo, no qual são traçadas metas para a sua utilização.

Têm-se consciência de que o levantamento realizado sobre as simulações computacionais disponíveis na Internet não esgotou o leque de possibilidade que esse meio de comunicação oferece. Entretanto, permitiu confirmar a qualidade das simulações 
computacionais disponível na plataforma PhET, bem como a viabilidade de seu uso no ensino de Física. Para tanto, o professor ao propor as simulações computacionais como recursos de ensino e aprendizagem deve ter consciência do potencial e limitações desse recurso, de modo que sua exploração não se transforme na mera substituição do professor pelo computador.

Sancionando nosso posicionamento de que as simulações computacionais se apresentam como mais um recurso de ensino, de maneira que a diversificação nos materiais didáticos aliado ao fazer docente ainda se apresenta como um fator importante na melhoria da qualidade do ensino.

Por fim, espera-se que este trabalho possa contribuir para outros professores que se sintam sensibilizados e desafiados a refletirem sobre a necessidade de mudanças nas práticas educativas com o melhor aproveitamento dos recursos tecnológicos nas escolas, particularmente nas escolas públicas.

\section{Referências}

ARANTES, A. et al. Objetos de aprendizagem no ensino de Física: usando simulações do Phet. Física na Escola, v.11, n.1, 2010.

BALADEZ, F. O passado, o presente e o futuro dos simuladores. Fasci-Tec, São Caetano do Sul, v.1, n. 1, p. 29-40, 2009.

BLAIDI, S. et al. Conexões com Física. São Paulo: Moderno, 2010.

BRASIL. Lei de Diretrizes e Bases da Educação Nacional (Art. 35 inciso 10). 1996. Disponível em: < http://www.planalto.gov.br/ccivil_03/leis/ L9394.htm >. Acesso: 05 ago. 2014.

PCN+ Ensino Médio. Orientação Educacionais Complementares aos Parâmetros Curriculares Nacionais. 2002. Disponível em: <http:www.sbfisica.org.br/arquivos/PCN_FIS.pdf>. 
Acesso em: 16 nov. 2014.

CARDOSO, S. et al. Simulação computacional aliada a teoria da aprendizagem significativa: uma ferramenta para o ensino e aprendizagem do efeito fotoelétrico. Caderno brasileiro de ensino de Física, Santa Catarina, v, 29, p. 891-934, 2012. Número especial 2.

FERRACIOLI, L. et al. Ambientes de modelagem computacional no aprendizado exploratório de Física. Caderno brasileiro de ensino de Física, Santa Catarina, v. 29, p. 679-707, 2012. Número especial 2.

FAPERJ. Rede Rio de Computadores: Introdução à linguagem Java (CBPF-NT-006/00). 2000. Disponível em: <http://www.rederio.br/ downloads/pdf/NT006_00.pdf >. Acesso em: 14 maio 2016.

HECKLER ,V. et al. O uso de simuladores, imagens e animações como ferramentas auxiliares no ensino/aprendizagem. Revista brasileira de ensino de Física, v. 29, n. 2, p. 267-273, 2007.

JUCA, S.R. O uso de simulação computacionais no ensino de Física: sugestão didática para exploração do tema Energia Mecânica. $42 \mathrm{f}$. Monografia (Graduação em Física) - Instituto de Física, Universidade Federal Fluminense, Niterói, 2013.

MACÊDO, J. et al. Simulações computacionais como ferramentas para o ensino de conceitos básicos de eletricidade. Caderno brasileiro de ensino de Física, Santa Catarina, v. 29, n p. 546-613, 2012. Número especial 2.

MARCONI, M. A.; LAKATOS, E. M. Fundamentos de metodologia Científica. 5. ed. São Paulo: Atlas, 2003.

MEC. Ensino médio inovador. 2009. Disponível em: <https://phet. colorado.edu/pt_BR/about>. Acesso em: 14 maio 2016.

MEDEIROS, A.Possibilidadese Limitações das Simulações Computacionais no Ensino da Física. Revista brasileira de ensino de Física, v. 24, n. 2, p. 77-85, 2002. 
PHET. Interactive Simulations da Universidade do Colorado. 2016. Disponível em: <https://phet.colorado.edu/pt_BR/about $>$. Acesso em: 14 maio 2016.

VOGLER, Macos. 0 uso de simulações em Java como objetos de aprendizagem no ensino de Física. 2004. Disponível em: <http://www. abenge.org.br/CobengeAnteriores/2004/artigos/01_504.pdf >. Acesso em: 14 maio 2016. 